- This paper presents a timely and relevant account of the characteristics of children attending assessment for dental extractions under general anaesthesia.

- Whilst most children are diagnosed with infection or caries, few present with clinical symptoms that would justify antibiotics.

- With evidence of inappropriate prescribing this paper is a useful reminder of the criteria for using antibiotics.

- Wide deviation from recommended antibiotic regimes underlines the need for guidance on the management of acute dento-alveolar infections in children.

- Variation in waiting times between referral, assessment and treatment under general anaesthesia raises concerns about service provision meeting local demand.

\title{
An investigation of therapeutic antibiotic prescribing for children referred for dental general anaesthesia in three community national health service trusts
}

\author{
H. Harte, ${ }^{1}$ N. O. A. Palmer ${ }^{2}$ and M. V. Martin ${ }^{3}$
}

\begin{abstract}
Objective To investigate antibiotic prescribing for paediatric dental patients requiring general anaesthesia.

Design A prospective clinical study of children referred for dental treatment under general anaesthesia.

Method Information was collected by way of a two-stage questionnaire for children attending three community NHS trusts for dental extractions under general anaesthesia between July 2001 and January 2003.

Results A total of 360 questionnaires were analysed. There was wide variation in the waiting times (0-278 days) between referral and treatment under general anaesthesia. Most children (53\%) attended with dento-alveolar abscess, 46\% with caries only and 1\% for orthodontic extractions. Antibiotics were prescribed to $52 \%$ of patients with an abscess and $32 \%$ with caries only. Only $16 \%$ of patients presented with moderate to severe pain, 5.5\% with diffuse swelling and $12 \%$ with a raised temperature. Antibiotics were prescribed for patients with diffuse swelling (63\%) and raised temperature (50\%) but also for patients with pain only (39\%) and localised swelling (52\%). Amoxicillin was the most frequently prescribed antibiotic (82\%), with wide variation in all antibiotic regimens.
\end{abstract}

Conclusion This study provides evidence of inappropriate prescribing of antibiotics to children referred for treatment under general anaesthesia with wide variations in the regimens employed. There was no conclusive evidence that long waiting times for definitive treatment influenced antibiotic prescribing. In some areas the delay for definitive treatment for this group of vulnerable patients was unacceptably long.

\footnotetext{
${ }^{1}$ Community Dental Officer, North Liverpool P.C.T. 3 Glendyke Road, Liverpool L18 6JR ${ }^{2}$ Part-time Lecturer, Department of Clinical Dental Sciences, University of Liverpool, Liverpool L69 3BX 3Senior Lecturer, Department of Clinical Dental Sciences, University of Liverpool, Liverpool L69 3BX

Correspondence to: Dr H. Harte, North Liverpool PCT, Dental Directorate, Rathbone Hospital, Mill Lane, Liverpool L9 7JP

Email:hania.harte@hotmail.com
}

Concerns about the overuse of antibiotics and the problems of emerging antimicrobial resistance have been well documented. ${ }^{1,2}$ In order to control the development and spread of resistant bacteria it is important to know the patterns of antibiotic prescribing in different situations and identify where clinical practice should be improved. ${ }^{3}$ Research has been done into therapeutic antibiotic prescribing by dental practitioners for adults, both in and out of the emergency setting, ${ }^{4-6}$ but there is a paucity of information relating to children. Palmer et $a .^{7}$ analysed prescriptions of antibiotics for children by a large population of dental practitioners in England and found evidence of inappropriate prescribing. This latter study, however, did not relate prescribing activity to any clinical situation.

One clinical situation where antibiotics may be indicated is the paediatric dental emergency where a general anaesthetic is indicated. It has been recognised that children requiring dental general anaesthesia have specific characteristics. They are typically young, anxious, with decayed and painful teeth, and are fearful of treatment under local anaesthesia. ${ }^{8-10}$ For this group of patients who present with a dentoalveolar abscess, it is not possible to provide the definitive treatment of drainage or dental extraction. Referral for a general anaesthetic may delay the resolving of

\begin{tabular}{|c|c|c|c|}
\hline \multicolumn{2}{|c|}{$\begin{array}{l}\text { Time delay from referral Number assessed } \\
\text { to assessment (days) }\end{array}$} & \multirow{2}{*}{$\begin{array}{c}\begin{array}{c}\text { Number prescribed } \\
\text { antibiotic }\end{array} \\
19\end{array}$} & \multirow{2}{*}{$\begin{array}{c}\begin{array}{c}\text { No diffuse swelling or } \\
\text { raised temperature } \\
\text { (antibiotic prescribed) }\end{array} \\
13\end{array}$} \\
\hline $0-2$ & 43 & & \\
\hline $3-7$ & 41 & 23 & 17 \\
\hline $8-14$ & 59 & 30 & 26 \\
\hline $15-28$ & 79 & 42 & 29 \\
\hline $29-60$ & 53 & 20 & 15 \\
\hline $61-90$ & 20 & 0 & 0 \\
\hline $91-120$ & 11 & 2 & 1 \\
\hline $121-180$ & 8 & 3 & 3 \\
\hline $181-240$ & 7 & 2 & 2 \\
\hline $241-278$ & 7 & 0 & 0 \\
\hline
\end{tabular}




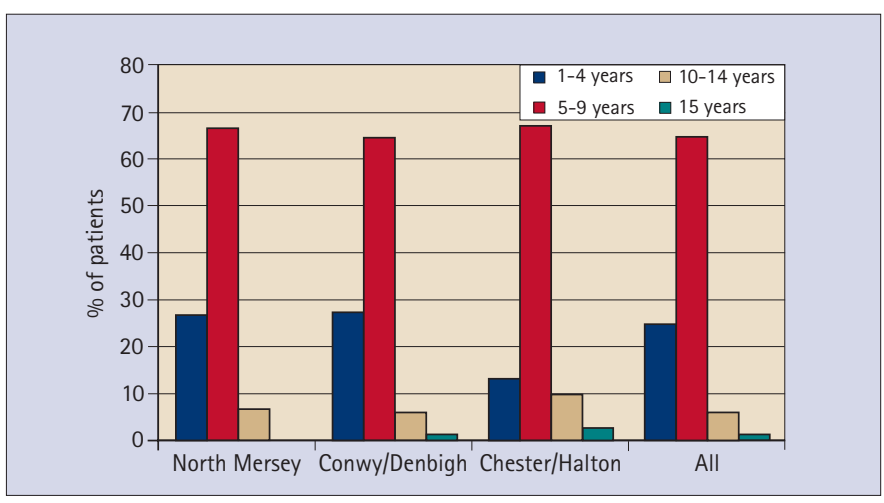

Fig. 1 Percentage distribution of age groups

infection, particularly since the Department of Health has restricted the provision of dental general anaesthesia to locations with access to critical care facilities. ${ }^{11}$ It has been suggested that when faced with a delay in treatment, a significant proportion of dentists will prescribe antibiotics. ${ }^{4}$

The aims of this study were to investigate the appropriateness of antibiotics prescribed for paediatric dental emergency patients requiring general anaesthesia, and the current antibiotic regimens being used.

\section{MATERIALS AND METHOD}

A questionnaire was devised to investigate children referred to the community dental clinics in three community NHS trusts for dental extractions under general anaesthesia. The participant trusts were North Mersey, Conwy and Denbighshire, and Chester and Halton, representing inner-city, rural and semi-rural areas respectively. Patients in North Mersey and Chester and Halton can be referred in by telephone, supported by a letter of referral; those in Conwy and Denbighshire are referred predominantly by letter only, to be prioritised and placed on a waiting list for treatment under general anaesthesia.

The questionnaire was initially piloted in North Mersey. The definitive data-collection instrument was a two-stage questionnaire completed for each patient at their assessment and treatment visits respectively. At assessment, information was collected on patient age and gender, the dates of both the original referral and assessment visit, and a clinical diagnosis that was recorded as abscess, caries or other. Information was also sought on the patient's clinically presenting condition with respect to pain, swelling and temperature.

Assessment of pain was done using a $10 \mathrm{~cm}$ Visual Analogue Scale (VAS). Where a patient was unable or reluctant to mark the

\begin{tabular}{|c|c|c|c|c|c|c|}
\hline \multirow[b]{2}{*}{$\begin{array}{l}\text { Time delay } \\
\text { from referral } \\
\text { to treatment } \\
\text { (days) }\end{array}$} & \multicolumn{2}{|c|}{ North Mersey } & \multicolumn{2}{|c|}{ Chester and Halton } & \multicolumn{2}{|c|}{ Conwy/Denbighshire } \\
\hline & $\begin{array}{l}\text { Number } \\
\text { treated }\end{array}$ & $\begin{array}{l}\% \\
\text { prescribed } \\
\text { antibiotic }\end{array}$ & $\begin{array}{l}\text { Number } \\
\text { treated }\end{array}$ & $\begin{array}{l}\% \\
\text { prescribed } \\
\text { antibiotic }\end{array}$ & $\begin{array}{l}\text { Number } \\
\text { treated }\end{array}$ & $\begin{array}{l}\% \\
\text { prescribed } \\
\text { antibiotic }\end{array}$ \\
\hline $1-7$ & 15 & 40 & 5 & 60 & 1 & 100 \\
\hline $8-14$ & 28 & 54 & 3 & 33 & 1 & 0 \\
\hline $15-28$ & 71 & 55 & 19 & 68 & 5 & 0 \\
\hline $29-60$ & 51 & 45 & 15 & 67 & 11 & 27 \\
\hline $61-90$ & 10 & 40 & 3 & 67 & 13 & 31 \\
\hline $91-120$ & 8 & 25 & 2 & 0 & 15 & 13 \\
\hline $121-180$ & - & - & - & - & 14 & 0 \\
\hline $181-240$ & - & - & - & - & 7 & 43 \\
\hline $241-300$ & - & - & - & - & 7 & 43 \\
\hline $301+$ & - & - & - & - & 7 & 0 \\
\hline
\end{tabular}

level of pain experienced the parent was asked to do this on behalf of their child. Swelling, where present, was classified by the assessing dentist as mild (localised, intra-oral only), moderate (diffuse, intra-oral only), severe (some facial involvement) or gross (severe facial swelling). These criteria were defined in an accompanying instruction sheet. Temperature was measured using a Feverscan forehead thermometer according to manufacturer's instructions. ${ }^{12}$

The first part of the questionnaire also investigated any antibiotics prescribed by a dentist prior to or on the day of the assessment, recording antibiotic name, dose, duration, frequency and formulation. Details of prior medication were obtained from either the parent or the letter of referral. A record was also made of any analgesics taken on the day, including time of intake, in order to account for their influence on pain and temperature.

The second part of the questionnaire was completed at the time of treatment under general anaesthesia by the operating dentist. The date of the treatment visit was noted and information was sought on the clinically presenting conditions with respect to pain, swelling and temperature using the same procedures as at assessment, together with any analgesics taken.

\section{Sample and data-handling}

The period for data collection was from July 2001 to January 2003. During this time each trust was encouraged to survey as many children as possible referred from both general dental practitioners and community dental officers. Excluded from the study were adult referrals, special needs cases and paediatric referrals for restorative procedures under general anaesthesia.

Training was provided to all assessing and operating dentists in all three trusts in a series of formal meetings, supported by written instructions. The questionnaires were pre-coded only to allow identification of each trust. The anonymity of the responding dentists, patients and their referring dentists was preserved. For this reason no cross-checking of prior medication was actively encouraged, with incomplete records excluded only in the analysis of antibiotic details.

The questionnaires received were entered into a Statistical Package for Social Science (SPSS) database and responses were analysed for frequencies. ${ }^{13}$ A Mann-Whitney test was used to investigate any relationship between parent and patient perceptions of pain. Chi-squared tests were used to investigate any significant changes in clinical presenting signs between assessment and treatment for those who had taken antibiotics and those who had not. For the purposes of analysis the following conventions were used: children diagnosed with both caries and abscess were coded only for abscess; pain levels were grouped into none, mild (0.5 - 3.5 $\mathrm{cm})$, moderate $(4.0-7.5 \mathrm{~cm})$ and severe $(8.0-10.0 \mathrm{~cm})$; temperature measurements were grouped into normal $\left(<=37.4^{\circ} \mathrm{C}\right)$, mild $\left(37.5-37.9^{\circ} \mathrm{C}\right)$ moderate $\left(38.0-38.4^{\circ} \mathrm{C}\right)$ and severe $\left(>=38.5^{\circ} \mathrm{C}\right)$.

\section{RESULTS}

A total of 360 questionnaires were returned, of which 217 were from North Mersey, 83 from Conwy and Denbighshire, and 60 from Chester and Halton. With a small number of patients failing to attend for assessment ( $n=3$ in North Mersey and $n=2$ in Chester and Halton) the results are based on a sample size of 355 useable questionnaires. This total represents $8.25 \%$ of the total number of children having a general anaesthetic for dental extractions during the study period throughout the three trusts $(n=4,299)$. Where appropriate, percentages have been adjusted to account for missing data.

The total sample was divided almost equally on gender with $49.5 \%$ males $(n=176)$ and 50.5\% females $(n=179)$. Ages ranged from 1 - 15 years with a mean of 6 years 1 month. Overall, 25\% of patients were aged $1-4$ years ( $n=89$ ), 67\% were aged 5 - 9 years $(n=234), 7 \%$ were aged $10-14$ years $(n=25)$ and $1 \%$ were aged 15 
years $(n=3)$. This distribution, as shown in Figure 1, was similar across all three trusts with the exception of Chester and Halton where there were fewer patients aged $1-4$ years (13\%) and more aged 10 - 14 years $(10 \%)$.

Of all children, 53\% ( $n=179)$ were diagnosed with an abscess, $46 \%(n=153)$ had caries only and $1 \%(n=4)$ required orthodontic extractions. The proportion of children assigned to each clinical diagnosis varied between trusts. In North Mersey 68\% $(n=140)$ of children had an abscess and 32\% ( $n=66)$ had caries only. In contrast, the majority of children in Conwy and Denbighshire, $(69 \%, n=56)$, and Chester and Halton, (65\%, $n=31)$, were diagnosed with caries.

Figure 2 shows that in North Mersey 57\% $(n=80)$ of children with an abscess and 30\% $(n=20)$ of those with caries only were prescribed antibiotics. In Conwy and Denbighshire, the respective figures were 39\% $(n=9)$ and 14\% ( $n=8)$. In Chester and Halton, antibiotics were prescribed to $62.5 \%(n=10)$ of children with an abscess and $52 \%(n=16)$ of those with caries only. Overall, antibiotics were prescribed to 52\% $(n=99)$ of children with an abscess and 32\% $(n=44)$ with caries only.

\section{Presenting clinical conditions at assessment}

A total of 55\% ( $n=194)$ of patients reported some experience of pain on the day of assessment but it was noted that only $4 \%$ $(n=16)$ of all patients had taken analgesics. Comparing reported pain experience across trusts, in North Mersey this figure was 51\%, in Conwy and Denbighshire 54\%, and Chester and Halton $69 \%$. In relation to clinical diagnosis 55\% $(n=84)$ of all children with caries only and 57\% $(n=102)$ of those with an abscess reported pain. In Chester and Halton these proportions were noticeably higher at 74\% and 69\% respectively.

Generally, the levels of reported pain were mild. The VAS was completed by $52 \%(n=163)$ of patients and $48 \%(n=149)$ of parents. Although statistical analysis shows that the parents' perception of pain was significantly higher than that reported by the patients (Mann-Whitney $U, \mathrm{z}=2.15, \mathrm{p}<0.05$ ) approximately $80 \%$ in each group scored no more than $3.5 \mathrm{~cm}$. Only 16\% $(n=56)$ of children had moderate to severe pain as represented by scoring $4.0 \mathrm{~cm}$ or more on the VAS. Of all the patients presenting with pain only, $39 \%(n=29)$ were given antibiotics.

With respect to swelling and temperature, 45\% ( $n=154)$ of all children presented with a swelling which in $12 \%$ of cases $(n=19)$ was moderate to severe; $12 \%(n=42)$ of children presented with an elevated temperature of $38^{\circ} \mathrm{C}$ and above. There was a noticeably higher proportion of children with a raised temperature (30\%, $n=16)$ in Chester and Halton. Relating the prescribing of antibiotics to the severity of these clinical conditions, antibiotics were prescribed to $63 \%(n=12)$ of children with a diffuse swelling and $52 \%$ ( $n=70$ ) with a localised swelling; of the 42 children with an elevated temperature $50 \%(n=21)$ were prescribed antibiotics. Overall, $22 \%$ $(n=73)$ of all referrals at assessment had no pain, swelling or

Table 3 Percentage distribution of changes in clinical conditions in relation to antibiotics prescribed and waiting times between assessment and treatment

\begin{tabular}{lllllll}
\hline & Pain & \multicolumn{3}{c}{ Swelling } & \multicolumn{2}{c}{ Temperature } \\
\hline \multirow{4}{*}{ No change } & antibiotic & no & antibiotic & no & antibiotic & no \\
antibiotic & & antibiotic & & antibiotic \\
& 36 & 53 & 78 & 82 & 70 & 69 \\
& $27^{*}$ & $35^{*}$ & $56^{*}$ & $56^{*}$ & $55^{*}$ & $49^{*}$ \\
& 19 & 18 & 22 & 26 & 15 & 20 \\
Improvement & 46 & 36 & 19 & 15 & 23 & 13 \\
& $34^{*}$ & $19^{*}$ & $10^{*}$ & $6^{*}$ & $11^{*}$ & $5^{*}$ \\
& 12 & 17 & 9 & 9 & 12 & 8 \\
& 18 & 11 & 3 & 3 & 7 & 18 \\
& $5^{*}$ & $5.5^{*}$ & $1.5^{*}$ & $2^{*}$ & $3^{*}$ & $6^{*}$ \\
& 13 & 5.5 & 1.5 & 1 & 4 & 12
\end{tabular}

[* patients waiting $0-13$ days between assessment and treatment. All other figures are for patients waiting 14+ days between assessment and treatment.]

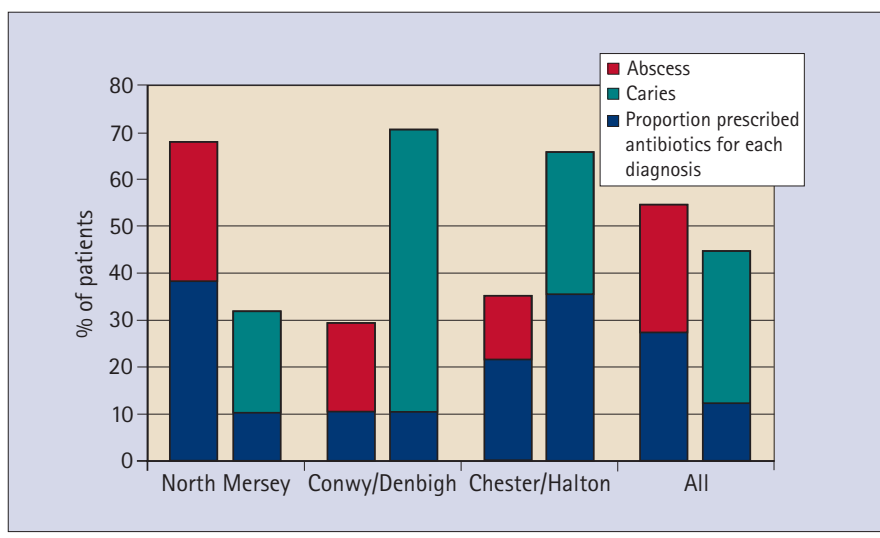

Fig. 2 Percentage of patients with abscess or caries and the proportion of patients prescribed antibiotics for each diagnosis $(n=332)$

temperature of which 30\% ( $n=22)$ were given antibiotics. Figure 3 shows the percentage distribution of these clinical conditions across the three trusts together with the proportion of patients prescribed antibiotics for each condition.

Overall, $43 \%$ of all patients ( $n=154)$ were prescribed antibiotics. The percentage of patients prescribed antibiotics in North Mersey was 48\% ( $n=103)$, Conwy and Denbighshire 20.5\% ( $n=17)$ and Chester and Halton 59\% $(n=34)$. Relatively few of these patients were prescribed antibiotics by the assessing dentist $(n=4)$. The majority of antibiotics were prescribed prior to assessment by the referring dentist, with some anecdotal evidence of additional prescribing by the patient's doctor. In North Mersey and Chester and Halton around $90 \%$ of prescriptions were given out before or at the referral visit. In Conwy and Denbighshire this figure was comparatively lower at 36\%, most antibiotics (46\%) being prescribed in the interim period between referral and assessment.

\section{Waiting times between referral and assessment}

The overall mean length of wait between referral and assessment was 36 days. North Mersey and Chester and Halton showed similar mean waiting times of 18 and 16 days respectively but the average length of wait for an assessment in Conwy and Denbighshire was 92 days. In North Mersey and Chester and Halton more than $80 \%$ of patients referred were seen within four weeks; in Conwy and Denbighshire 24\% of patients were seen within four weeks, whilst 31\% had to wait more than three months.

Table 1 shows the number of patients assessed and prescribed antibiotics in relation to the time delay from referral and the absence of either a diffuse swelling or raised temperature. Of the 84 children seen within one week of referral 50\% $(n=42)$ were prescribed antibiotics where $71 \%$ of them $(n=30)$ had neither an elevated temperature nor swelling. Of the 43 children assessed within two days of referral, 19 were prescribed antibiotics of which 13 were without symptoms of raised temperature or swelling.

\section{Waiting times between assessment and treatment}

Following assessment, the overall mean wait for treatment was 21 days, although this varied between the three trusts. North Mersey and Chester and Halton had mean waiting intervals of 11 and 17 days respectively, but for Conwy and Denbighshire this was 47 days. A negligible number of patients overall $(n=2)$ received antibiotics between assessment and treatment.

It can be seen from Table 2 that in North Mersey and Chester and Halton, prescribing activity throughout the time delay from referral to treatment remained steady with approximately $45 \%$ and $65 \%$ of patients respectively reporting having been prescribed antibiotics. In contrast, in Conwy and Denbighshire the proportion of patients reporting antibiotic prescriptions fluctuated unpredictably between $0 \%$ and $100 \%$ across the time delays. 


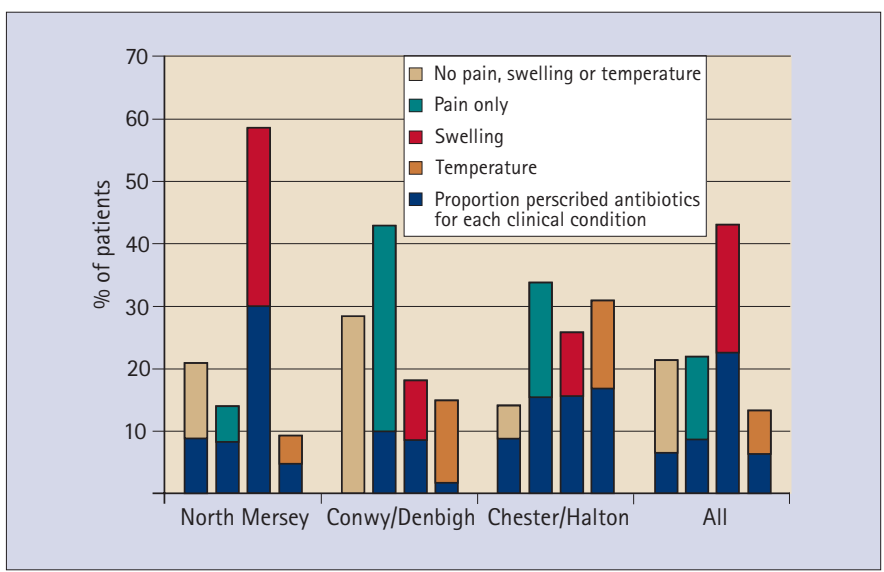

Fig. 3 Percentage of patients with pain, swelling or temperature, and the proportion of patients prescribed antibiotics for each condition $(n=329)$

Table 3 shows the changes in clinical conditions at treatment of patients who had taken antibiotics compared with those who had not. Up to $10 \%$ more patients in the antibiotic group showed improvements in pain, swelling and temperature when compared with the non-antibiotic group. In the antibiotic group there were only statistically significant improvements with respect to pain $\left(\chi^{2}\right.$ $=12.34, \mathrm{df}=2, p<0.01)$ and temperature $\left(\chi^{2}=11.77, \mathrm{df}=2, p<\right.$ $0.01)$. The proportions of patients who experienced no change in either swelling (80\%) or temperature (70\%) were similarly high among both groups. More than two-thirds of these patients were treated within two weeks from assessment.

By incorporating waiting times between assessment and treatment into the analysis the results show that, compared to those who had taken antibiotics, proportionately more children in the non-antibiotic group improved in the long-term than in the shortterm although the improvements were not statistically significant for either swelling $\left(\chi^{2}=0.41, \mathrm{df}=1, p>0.1\right)$ or temperature $\left(\chi^{2}=\right.$ $0.29 \mathrm{df}=1, p>0.1)$. In the antibiotic group there was only one statistically significant improvement in the short term, which related to pain $\left(\chi^{2}=6.63, \mathrm{df}=1, p<0.01\right)$.

Of all the patients known to have received antibiotics, the regimens prescribed were detailed in full for 72 (47\%) cases. These are shown in Table 4. The most prescribed antibiotic was amoxicillin (82\%), followed by penicillin (13\%), erythromycin (3\%) and metronidazole $(2 \%)$. The majority of prescriptions were in liquid form (98\%) of which $41 \%$ were specifically recorded as being for sugar-free formulations. Most courses of treatment (77\%) were of 5 days' duration, 16\% were prescribed for 7 days and 7\% were prescribed for 3 days.

\section{DISCUSSION}

As has been shown in previous studies ${ }^{14-16}$ the majority of children receiving dental general anaesthesia (67\%) were aged 5 - 9 years. It is of note that children aged $0-4$ years formed a much smaller proportion in Chester and Halton (13\%), a difference which is likely to relate to caries prevalence. The results of a recent dental survey of caries experience in five-year-old children in England and Wales indicate a higher caries prevalence in Liverpool $\left(\mathrm{d}_{3} \mathrm{mft}=2.30\right)$ and North Wales $\left(\mathrm{d}_{3} \mathrm{mft}=1.86\right)$ than in West Cheshire $\left(\mathrm{d}_{3} \mathrm{mft}=1.30\right)$ and Halton $\left(\mathrm{d}_{3} \mathrm{mft}=1.21\right) .{ }^{17}$

In comparison with previous studies ${ }^{18-21}$ where rates of referral for extractions as a result of caries, irrespective of sepsis, ranged from $86 \%$ - 94\% this study demonstrated a higher proportion (99\%). Only $1 \%$ of patients were referred for orthodontic purposes. This compares favourably with an equivalent rate of $4 \%$ found in a study by Clayton and Mackie ${ }^{21}$, suggesting the continuing reluctance of dentists to use general anaesthesia for elective extractions.

The majority of children in North Mersey referred for a general anaesthetic in this study attended with an abscess (68\%). In Conwy and Denbighshire, and Chester and Halton, however, the majority were referred for removal of teeth due to caries only (69\% and 65\% respectively). The greater proportion in North Mersey of children with infections associated with carious teeth is likely to be only partly the consequence of higher caries prevalence and low uptake of dental treatment where, surprisingly, in Liverpool the care index percentage of $10 \%$ is twice that of Halton (5\%). ${ }^{17}$ A contributory factor in explaining the difference in clinical diagnosis recorded is inter-examiner variability. This problem is evident within this study. Approximately 24\% of patients diagnosed with caries only in both Conwy and Denbighshire and Chester and Halton presented with clinical signs of sepsis, namely a swelling with or without a raised temperature; this compares with only $9 \%$ of patients in North Mersey. Whilst swelling may or may not accompany an infection, its presence makes it difficult to support a diagnosis made by the examiners of caries only. Within this study it was evident that referring dentists prescribed antibiotics in the absence of infection (North Mersey 30\%, Conwy and Denbighshire 14\%, and Chester and Halton 52\%).

Previous research has shown that while practitioners are more likely to prescribe antibiotics to children in the presence of infection and swelling, 12\% will prescribe for infection without swelling. ${ }^{22}$ This suggests that pain is a significant factor in prompting antibiotic prescribing. Pain has been found difficult to evaluate in children, ${ }^{23}$ being influenced on occasion by variables related to both personal and parental experience. ${ }^{24}$ Without any accompanying evidence of spreading infection or elevated temperature it is wholly inappropriate as the sole indicator for antibiotics. In this study 39\% of all patients presenting with pain only were prescribed antibiotics.

It is interesting to note that despite more than half of all children reporting pain at assessment (55\%) only 4\% admitted to having taken analgesics that day. This does concur, however, with the majority of patients (80\%) reporting only mild pain despite significantly higher scores given by parents in this study, although as research shows, there is some likelihood of parents exaggerating the intensity of illness. ${ }^{25}$

The evidence from this study relating antibiotic prescribing to the severity of presenting swelling and temperature also suggests injudicious prescribing of antibiotics. Whilst $63 \%$ of all children with a diffuse intra-oral swelling were given antibiotics, so too were $52 \%$ of children with a localised swelling. In contrast, antibiotics were prescribed to only 50\% of all children with an elevated temperature of $38^{\circ} \mathrm{C}$ and above where there is a strong indication to prescribe.

It is important to note that most antibiotics were prescribed prior to assessment. For patients given antibiotics their presenting clinical conditions at assessment may have changed from those at referral as a consequence of antibiotics already taken. An added

\begin{tabular}{|c|c|c|c|c|c|}
\hline $\begin{array}{l}\text { Antibiotic } \\
\text { prescribed }\end{array}$ & Dose & Frequency & Duration & $\begin{array}{l}\% \\
\text { prescriptions }\end{array}$ & $\begin{array}{l}\text { Ages at } \\
\text { which given }\end{array}$ \\
\hline \multirow[t]{6}{*}{ Amoxicillin } & $125 \mathrm{mg}$ & $3 x$ daily & 5 days & 52 & $2-10$ \\
\hline & $125 \mathrm{mg}$ & $3 x$ daily & 7 days & 10 & $6-8$ \\
\hline & $250 \mathrm{mg}$ & $3 x$ daily & 5 days & 7 & $4-12$ \\
\hline & $125 \mathrm{mg}$ & $3 x$ daily & 3 days & 6 & $3-5$ \\
\hline & $250 \mathrm{mg}$ & $3 x$ daily & 7 days & 4 & $5-8$ \\
\hline & $125 \mathrm{mg}$ & $4 x$ daily & 5 days & 3 & $6-7$ \\
\hline \multirow[t]{4}{*}{ Penicillin } & $250 \mathrm{mg}$ & $4 x$ daily & 5 days & 7 & $6-10$ \\
\hline & $125 \mathrm{mg}$ & $4 x$ daily & 5 days & 4 & $5-9$ \\
\hline & $125 \mathrm{mg}$ & $4 x$ daily & 7 days & 1 & 10 \\
\hline & $250 \mathrm{mg}$ & $3 x$ daily & 7 days & 1 & 6 \\
\hline Erythromycin & $125 \mathrm{mg}$ & $4 x$ daily & 5 days & 3 & $4-7$ \\
\hline \multirow[t]{2}{*}{ Metronidazole } & $200 \mathrm{mg}$ & $3 x$ daily & 3 days & 1 & 4 \\
\hline & $200 \mathrm{mg}$ & $3 x$ daily & 5 days & 1 & 9 \\
\hline
\end{tabular}


consideration here must be the length of time lapse from referral to assessment. The results show that $30 \%(n=13)$ of patients seen within two days of referral with neither swelling nor elevated temperature had been prescribed antibiotics. This proportion increased to $36 \%(n=30)$ for the total number of patients assessed within the first week. Allowing for a short period of time, often quoted as two days ${ }^{26}$ in which antibiotics begin to take effect, one would expect patients clinically in need of antibiotics to still be showing some of the symptoms that justified the original prescription.

The evidence of inappropriate prescribing appears convincing, despite the retrospective nature of the study. This may be the consequence of several factors, both clinical and non-clinical, already identified in previous studies. ${ }^{4}$ These include poor knowledge of therapeutic prescribing, pressure of time and workload, uncertainty of diagnosis and where treatment is delayed. The unknown delay between referral and definitive treatment would appear to influence dentists' management of children who require general anaesthetic management of their dental problems. Referring dentists in North Mersey and Chester and Halton can telephone the community dental clinic for a pre-general anaesthetic assessment appointment, but they are unlikely to know of the time delay for treatment. In Conwy and Denbighshire the use of only referral letters adds to the uncertainty of the waiting times for assessment and definitive treatment. It is interesting to note the higher percentage of children (46\%) in Conwy and Denbighshire prescribed antibiotics after referral while awaiting assessment. This would concur with anecdotal evidence that suggests that the long wait for an assessment appointment results in many patients seeking help several times from both dentists and doctors.

When comparing clinical conditions between assessment and treatment it would appear that patients with antibiotics demonstrated slightly higher frequencies of reduced pain, swelling and temperature than those without. This should be set against the considerably greater proportions of patients (around 75\%) who experienced no change in either swelling or temperature, irrespective of antibiotics. Moreover, more than two-thirds of these patients were seen within two weeks of assessment, when one might have expected to see more evidence of therapeutic impact had the clinical need originally existed. Proportionately more children in the long term improved clinically in terms of swelling and temperature without having had antibiotics. If waiting times are to increase this should suggest that, unless clinically justified, there is little merit in resorting to antibiotics in the hope of long term amelioration of symptoms.

The variation in choice of antibiotic closely mirrors the findings of previous research. ${ }^{7}$ The range of regimens used in this study highlights a similarly significant deviation from current recommendations. The duration of the majority of prescriptions, for example, was in excess of the two to three days recommended for amoxicillin ${ }^{27}$ while some doses for penicillin were too low for the age of the patient, answering a question posed by Palmer et al. ${ }^{7}$ concerning relationships of dosage to age. The wide deviation from recommended antibiotic regimens suggest a need for guidance on the management of acute dentoalveolar infection in children awaiting general anaesthesia.

In conclusion, whilst the factors that prompted the prescribing of antibiotics were the presence of sepsis, swelling and raised temperature they also included caries and clinical conditions too mild to justify antibiotic therapy. In particular, the presence of pain was found to be a motivating factor. It is interesting to note that only $4 \%$ of patients admitted to having taken analgesics. Yet this compares with a previous study where, in a similar sample size of caries-related emergencies, only $7 \%$ were prescribed analgesics. ${ }^{28}$ There is a need to educate practitioners on the use of analgesics to manage pain whilst awaiting the provision of definitive treatment.

From this limited study there is no conclusive evidence that long waiting times are exacerbating the problem of over-prescribing or inappropriate prescribing of antibiotics but this possibility cannot be dismissed. In areas where the waiting times for both assessment and treatment are unacceptably long there is anecdotal evidence of multiple courses of antibiotics and this requires further investigation. It is unacceptable that children who require a general anaesthetic to deal with dental pain, with or without the presence of infection, should have to wait for definitive treatment. Purchasers of services should review service provision to ensure that this vulnerable group of patients receive a first class service.

The authors would like to thank Dr A. Osuhor and Dr P. J. Young (North Mersey), Dr J. S. Sandham and Dr J. A. Clewett (Conwy and Denbighshire), Dr L .I. Gough and Dr S. M. Stewart (Chester and Halton) and Mrs Helen Purdy for their assistance. This study was supported by the Spread II initiative.

1. Wise R, Hart T, Cars O, et al. Antimicrobial resistance is a major threat to public health BrMed J 1998; 317: 609-610.

2. Standing Committee of Science and Technology House of Lords. Resistance to antibiotics and other microbial agents. London: The Stationary Office, 1998.

3. Huoven P, Cars O. Control of antimicrobial resistance: time for action. Br Med J 1998; 317: 613

4. Palmer N O A, Pealing R, Ireland R S, Martin M V. A study of therapeutic antibiotic prescribing in National Health Service general dental practice in England. Br Dent $J$ 2000; 188: 554-558.

5. Palmer N O A, Martin M V, Pealing R, et al. Antibiotic prescribing knowledge of National Health Service general dental practitioners in England and Scotland. $J$ Antimicrob Chemother 2001; 47: 233-237.

6. Thomas D W, Satterthwaite J, Absi E G, Lewis M A O, Shepherd J P. Antibiotic prescription for acute dental conditions in the primary care setting. Br Dent J 1996 181: 401-404.

7. Palmer N O A, Martin M V, Pealing R, Ireland R S. Paediatric antibiotic prescribing by general dental practitioners in England. Int Paediatr Dent 2001; 11: 242-248.

8. Carson P, Freeman R. Characteristics of children attending for dental general anaesthesia in 1993 and 1997. Prim Dent Care 2000; 7: 163-167.

9. Vermeulen $M$, Vinckier $F$, Vandenbroucke J. Dental general anaesthesia: clinical characteristics of 933 patients. J Dent Child 1991; 58: 27-30.

10. Enger D J, Mourino A P. A survey of 200 paediatric dental general anaesthesia cases. Dent Child 1985; 52: 36-41.

11. A conscious decision. A review of the use of general anaesthesia and conscious sedation in primary dental care. London: Department of Health, 2000.

12. Boots Feverscan Forehead Thermometer, Robinson and Sons Ltd., The Boots Company PLC, Nottingham, England, 1999

13. SPSS for Windows Base Version. 11.0 ed. Chicago IL 60611: SPSS Inc., 1998.

14. Holt R D, Al Lamki S, Bedi R, Dowey J A, Gilthorpe M. Provision of dental general anaesthesia for extractions in child patients at two centres. Br Dent J 1999; 187 498-501.

15. Holt R D, Davenport ES, Fung D E. The use of general anaesthesia for tooth extraction in children in London: a multi-centre study. Br Dent J 1992; 173:333-339.

16. Smallridge J A, Al Ghanim N, Holt R D. The use of general anaesthesia for tooth extraction for child outpatients at a London dental hospital. Br Dent J 1990; 168 : 438-440.

17. Pitts N B, Boyles J, Nugent Z J, Thomas N, Pine C M. The dental caries experience of 5 year-old children in England and Wales, 2001/2002. British Association for the Study of Community Dentistry co-ordinated NHS dental epidemiological survey of 5-yearold children. Commun Dent Health 2003; 20: 45-54.

18. Holt R D, Rule D C, Davenport E S, Fung D E. The use of general anaesthesia for tooth extraction in children in London: a multi-centre study. Br DentJ 1992; 173: 333-339.

19. Landes D P, Bradnock G. Demand for dental extractions performed under genera anaesthesia for children by Leicester community dental service. Community Dent Health 1996; 13: 105-115.

20. MacCormac $C$, Kinirons M. Reasons for referral of children to a general anaesthetic service in Northern Ireland. Int J Paediatr Dent 1998; 8: 191-196.

21. Clayton $M$, Mackie I C. The development of referral guidelines for dentists referring children for extractions under general anaesthesia. Br Dent J 2003; 194: 561-565.

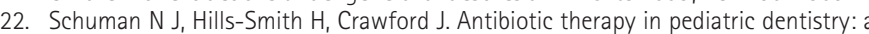
survey. J Oral Med 1983; 38: 123-126.

23. Abu-Saad H. Assessing childrens' responses to pain. Pain 1984; 16: 163-171.

24. Acs G, Moore P. Pain and analgesic consumption in children following dental extractions. J Dent Res 1984; 63: 265 (Abstract).

25. Charney E, Bynum $R$, Eldredge $D$ et al. How well do patients take oral penicillin? A collaborative study in private practice. Pediatr 1967; 40: 188-195.

26. Dental Practitioners Formulary 2002-2004, British National Formulary No 44. London: The Royal Pharmaceutical Society of Great Britain and the British Medical Association.

27. Martin M V , Longman L $P$, Hill J B, Hardy P. Acute dentoalveolar infections: an investigation of the duration of antibiotic therapy. Br Dent J 1997; 183: 135-137.

28. Sheller B, Williams B J, Lombardi S M. Diagnosis and treatment of dental cariesrelated emergencies in a children's hospital. Pediatr Dent 1997: 19: 470-475. 